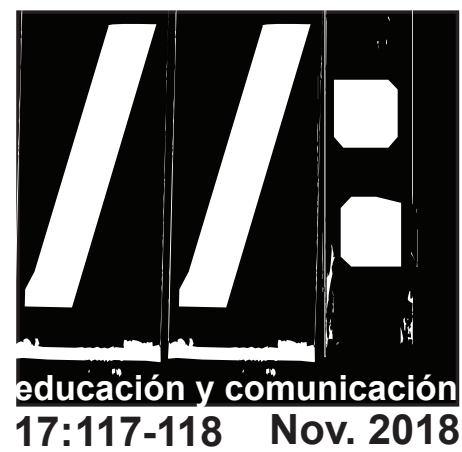

Carmen Moguel

Grupo de investigación HUM 818

"Educación y Comunicación"

Universidad de Cádiz

\section{LA UNIVERSIDAD GOMO SUJETO TRANSFORMADOR DE LA REALIDAD SOCIAL EN MATERIA DE IGUALDAD DE GÉNERO}

Autores. Varios

Año: 2018

Editorial: Consejería de igualdad y política sociales Localidad: Sevilla 


\section{IIA Educación y comunicación en los mundos de fantasía y ficción}

$\mathrm{L}$ os libros son más que útiles, son necesarios e imprescindibles. A través de ellos se transmiten los conocimientos y saberes que contribuyen a mejorar la vida, la cotidianeidad de las personas. Y este es el caso de la presente obra colectiva con el sugestivo título de La Universidad como sujeto transformador de la realidad social en materia de igualdad de género, publicado por la Consejería de Igualdad y Políticas Sociales de la Junta de Andalucía.

Un libro plural, con un componente bipartito: la Universidad de Cádiz y la Universidad de San Carlos de Guatemala. Que atesora un componente más, que la mayoría de los textos aquí publicados fueron el motivo inspirativo de conferencias y encuentros a ambos lados del Atlántico, durante el año 2017, dividido en tres segmentos: derecho, educación y comunicación. Los contenidos que aparecen en los artículos son de lo más variado. Pero me gustaría reflejar y someter a su juicio que tal como dijera el pedagogo brasileño, Paulo Freire, hay que saber "leer el mundo". Está claro que sí. ¿Quién lo discutiría? Pero también hay que escribir en el mundo (aportar); del mismo modo, que se ha de reescribir el mundo (reinterpretarlo). Sobre todo, en materia de igualdad, la mujer, el género, la diversidad o la violencia.

En este sentido, la perspectiva de género se hace necesaria y útil a la hora de aportar y reinterpretar la presencia y posición de la mujer en el mundo, con su violencia, causas y consecuencias que se expanden o amplifican a través de los medios de comunicación, también los nuevos media (Internet).

El ámbito político abre la caja de pandora. La comunicación pone freno a las exageraciones que bombardean a la red de receptores. Y la educación requilibra los flujos de la incomprensión. Y cuando acaben de leer este libro, tal vez, terminen con más preguntas que supuestas respuestas sobre el papel de la Universidad en esto de la transformación de la realidad social en materia de igualdad de género. Sea lo que fuera, podría llegar a sufrir aparentes agujetas sensitivas e intelectuales. Ahora más que nunca, o como siempre, hace falta capacidades e instrumentos de transformación de realidades tan obsoletas como las desigualdades.

Un libro que se lee con literatura del pasado pero que tiene una importante proyección en el futuro. El de los mujeres y los hombres que vengan a contribuir a la igualdad de género, para ir acabando de una vez por todas con aquellas realidades irracionales vinculadas a desajustes sociales, económicos, políticos, además de las consabidas en el ámbito de lo jurídico, comunicativo y educativo.

Un libro necesario, igual o más que nunca. Unos encuentros que ojalá siembren las semillas sobre la igualdad que han de germinar entre nosotras y nosotros pero, también, entre las generaciones venideras. Por ello, la Universidad tiene que abanderar estas iniciativas. Por eso, se ha de continuar en el tiempo y en la labor. A sabiendas que ya hay algo iniciado para Panamá.

En gran medida, también desde América Latina se han de llevar a cabo iniciativa de este tipo y mirar y mirarnos los unos en los otros para mejorar.

La Universidad como acicate para la transferencia del conocimiento, de experiencia... del saber. Tal como dice la contraportada del libro "con el objetivo de fortalecer y visualizar la temática de género y liderar procesos de cambio en materia de igualdad como agentes de conocimiento e investigación". 